\title{
Reservoirs of antimicrobial resistance genes in retail raw milk
}

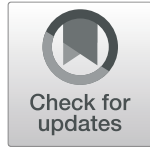

Jinxin Liu ${ }^{1,2}$, Yuanting Zhu ${ }^{1,2}$, Michele Jay-Russell ${ }^{3}$, Danielle G. Lemay ${ }^{4,5,6}$ and David A. Mills $s^{1,2,7^{*}}$ (D)

\begin{abstract}
Background: It has been estimated that at least 3\% of the USA population consumes unpasteurized (raw) milk from animal sources, and the demand to legalize raw milk sales continues to increase. However, consumption of raw milk can cause foodborne illness and be a source of bacteria containing transferrable antimicrobial resistance genes (ARGs). To obtain a comprehensive understanding of the microbiome and antibiotic resistome in both raw and processed milk, we systematically analyzed 2034 retail milk samples including unpasteurized milk and pasteurized milk via vat pasteurization, high-temperature-short-time pasteurization, and ultra-pasteurization from the United States using complementary culture-based, 16S rRNA gene, and metagenomic sequencing techniques.

Results: Raw milk samples had the highest prevalence of viable bacteria which were measured as all aerobic bacteria, coliform, and Escherichia coli counts, and their microbiota was distinct from other types of milk. 16S rRNA gene sequencing revealed that Pseudomonadaceae dominated raw milk with limited levels of lactic acid bacteria. Among all milk samples, the microbiota remained stable with constant bacterial populations when stored at $4{ }^{\circ} \mathrm{C}$. In contrast, storage at room temperature dramatically enriched the bacterial populations present in raw milk samples and, in parallel, significantly increased the richness and abundance of ARGs. Metagenomic sequencing indicated raw milk possessed dramatically more ARGs than pasteurized milk, and a conjugation assay documented the active

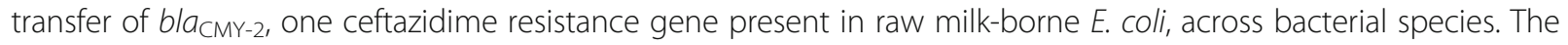
room temperature-enriched resistome differed in raw milk from distinct geographic locations, a difference likely associated with regionally distinct milk microbiota.
\end{abstract}

Conclusion: Despite advertised "probiotic" effects, our results indicate that raw milk microbiota has minimal lactic acid bacteria. In addition, retail raw milk serves as a reservoir of ARGs, populations of which are readily amplified by spontaneous fermentation. There is an increased need to understand potential food safety risks from improper transportation and storage of raw milk with regard to ARGs.

Keywords: Raw milk, Antimicrobial resistance, Metagenomics, Public health

\footnotetext{
*Correspondence: damills@ucdavis.edu

'Department of Food Science and Technology, Robert Mondavi Institute for

Wine and Food Science, University of California, Davis, One Shields Ave,

Davis, CA 95616, USA

${ }^{2}$ Foods for Health Institute, University of California, Davis, One Shields Ave, Davis, CA 95616, USA

Full list of author information is available at the end of the article
}

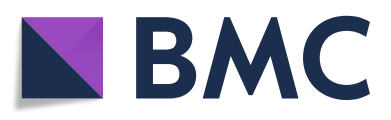

(c) The Author(s). 2020 Open Access This article is licensed under a Creative Commons Attribution 4.0 International License, which permits use, sharing, adaptation, distribution and reproduction in any medium or format, as long as you give appropriate credit to the original author(s) and the source, provide a link to the Creative Commons licence, and indicate if changes were made. The images or other third party material in this article are included in the article's Creative Commons licence, unless indicated otherwise in a credit line to the material. If material is not included in the article's Creative Commons licence and your intended use is not permitted by statutory regulation or exceeds the permitted use, you will need to obtain permission directly from the copyright holder. To view a copy of this licence, visit http://creativecommons.org/licenses/by/4.0/ The Creative Commons Public Domain Dedication waiver (http://creativecommons.org/publicdomain/zero/1.0/) applies to the data made available in this article, unless otherwise stated in a credit line to the data. 


\section{Background}

Unpasteurized milk for human consumption is currently legalized for sale in 30 states either in retail stores $(n=13)$ or at local farms $(n=17)[1]$ in the USA, and the demand for raw milk is increasing [2, 3]. Despite the proposed health benefits of raw milk for humans [4-6], contamination of raw milk with zoonotic pathogens including Campylobacter spp., Shiga toxin-producing Escherichia coli, and Salmonella enterica have been well documented leading to serious illnesses [7-11]. In addition to the presence of potential pathogenic bacteria, raw milk contains antibiotic-resistant microbes [12-16], and thus the incorporation of raw milk into daily diet may facilitate the dissemination of antimicrobial resistance genes (ARGs) to the human gastrointestinal tract. At present, a comprehensive understanding of the antibiotic resistome in raw milk is lacking.

The raw milk microbiota has been documented in several studies, but has mostly focused on the milk at farms or during transportation [17-19]. However, in-depth investigations employing high throughput sequencing to examine the microbiota of raw milk at retail stores remain limited. In addition, there is little information on the extent to which the milk microbiota responds to various levels of pasteurization and processing. Raw fluid milk is typically directly consumed; however, it is sometimes deliberately left at room temperature (RT) for 1-5 days to make a product termed clabber [20]. Currently, the production of this "naturally fermented" milk is increasing with the public's interest in traditional foods $[21,22]$. Therefore, it is imperative to understand the dynamic changes of bacterial load, microbiota composition, and resistome content of raw milk during such incubations.

To examine this, a total of 2034 retail milk samples were collected from stores in California, Idaho, Arizona, South Carolina, and Maine. Eight milk brands in California representing 4 types of commercial milk processing (raw, vat pasteurized [Vat], high-temperature short time [HTST], ultra-pasteurized [UHT]) were sampled from 8 independent batches over five months. Vat pasteurization is the original method of pasteurization, which heats milk (typically at $145^{\circ} \mathrm{F}$ ) in a large tank for at least $30 \mathrm{~min}$. HTST pasteurization, the most common method of pasteurization in the USA, requires the milk temperatures to be at least $161^{\circ} \mathrm{F}$ for not less than $15 \mathrm{~s}$, followed by rapid cooling. Compared to HTST, UHT pasteurizes milk at an even higher temperature $\left(280^{\circ} \mathrm{F}\right)$ for $2 \mathrm{~s}$ and provides extended shelf-life of milk [23]. Collected milk samples were incubated at both $4{ }^{\circ} \mathrm{C}$ and $23^{\circ} \mathrm{C}$ for up to $24 \mathrm{~h}$, and the live bacterial load and milk microbiota were characterized during this period. Retail raw milk samples were also obtained in other states from 3 independent purchases for microbiota profiling. The milk resistome was characterized via metagenomic sequencing in selected milk samples. Via extensive sampling, culturing, and sequencing, this study expands our understanding of the microbiota composition and antibiotic resistome of retail milks as well as their response to pasteurization, geography, temperature, and spontaneous fermentation. These findings highlight the potential risk for ingestion and transfer of antimicrobial resistance when consuming raw milk.

\section{Results}

The dynamics of viable bacterial populations in various types of California retail milk during incubations

In order to explore the milk microbiota and antibiotic resistome, it was relevant to first quantify the viable bacteria and understand their dynamic change over incubations across various types of retail milk. In California, retail raw milk samples showed overall higher populations of live bacteria compared to retail milk samples that had been pasteurized. Prior to any incubations, raw milk had the highest absolute abundance of aerobic bacteria $(\sim 2.56-\log )$, followed by Vat (Dunn test, $P=0.14)$, HTST $(P<0.001)$, and UHT $(P<0.001)$ (Fig. 1a). Coliforms were present in a similar distribution across milk types, with raw milk containing the most bacteria $(\sim$ $1.05-\log )$ which was slightly higher than Vat $(P=0.36)$ and significantly more prevalent than HTST and UHT milks (Dunn test, $P<0.01$ in both cases, Fig. 1a). There was no measurable significant difference in the population of $E$. coli across milk types (Dunn test, $P>0.05$, Fig. 1a). At all levels, the bacterial population quantified remained stable in a cold environment $\left(4^{\circ} \mathrm{C}\right)$ over $24 \mathrm{~h}$ except a drop of $E$. coli at $4 \mathrm{~h}$ in raw milk (Supplementary figure 1).

According to The California Department of Food and Agriculture (CDFA), it is unlawful to distribute raw milk which contains more than 15,000 bacteria per milliliter or more than 10 coliform bacteria per milliliter [24]. Given that milk can be unintentionally (e.g., cold chain disruption) or intentionally (e.g., clabber) incubated at room temperature, retail milk samples were examined during a controlled RT incubation. During RT incubation, aerobic bacteria were significantly enriched in Raw, Vat, and HTST milk starting at $6 \mathrm{~h}, 12 \mathrm{~h}$, and $24 \mathrm{~h}$, respectively (LMM, $P<0.05$, Fig. 1b). As a result, the abundance of aerobic bacteria was beyond the CDFA regulations at $12 \mathrm{~h}$ in raw and $24 \mathrm{~h}$ in Vat milk (Fig. 1b). We observed a significant enrichment of coliforms in raw milk beginning at $12 \mathrm{~h}(\mathrm{LMM}, P<0.001)$ and in Vat milk starting at $24 \mathrm{~h}(\mathrm{LMM}, P<0.05)$, which surpassed the CDFA regulations (Fig. 1c). No significant changes of coliform counts were observed in HTST and UHT milk (LMM, $P>0.05$, Fig. 1c). Finally, the population of E. coli indicated a significant increase by the end of 


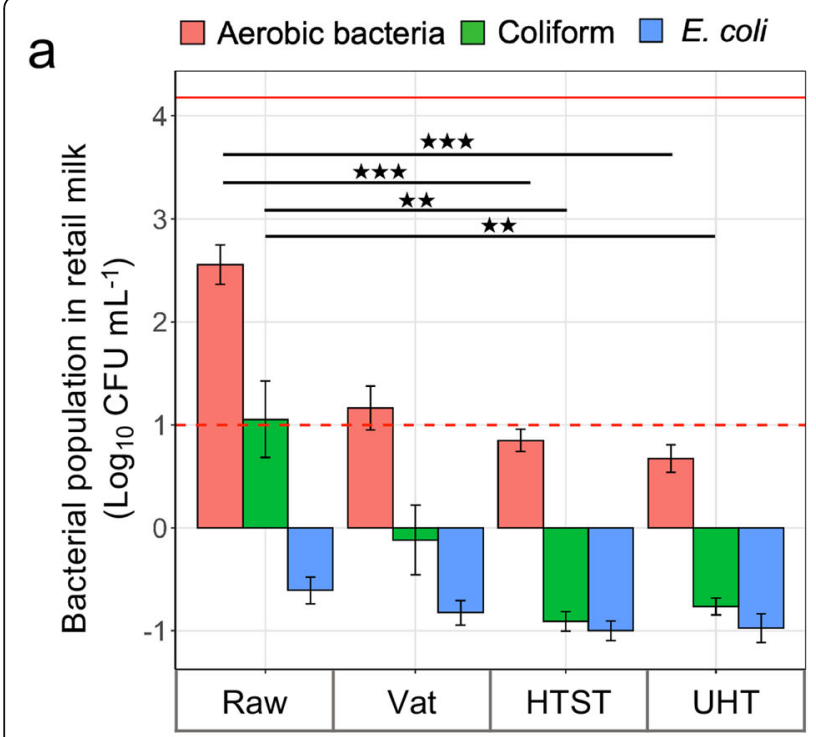

C
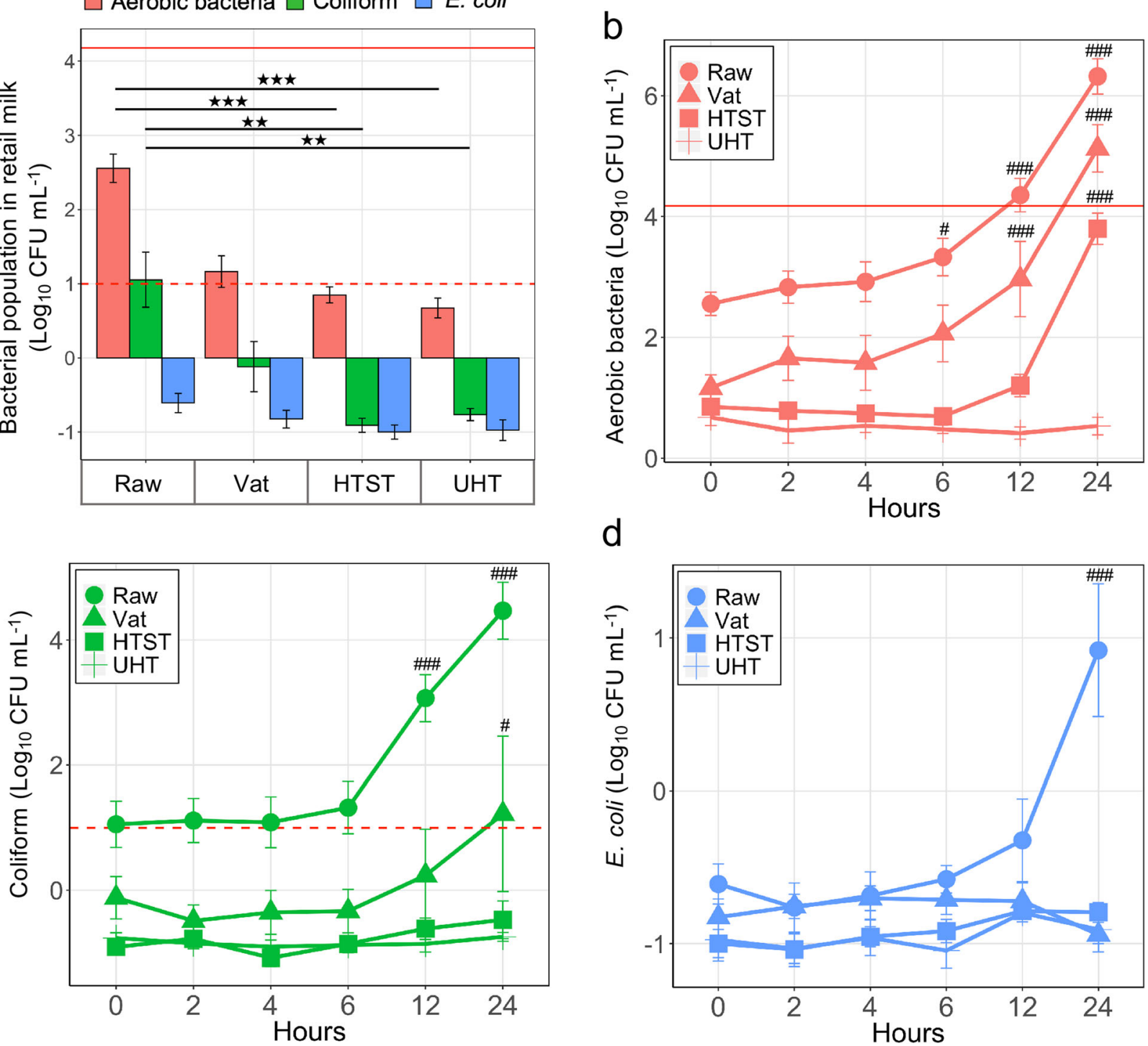

d

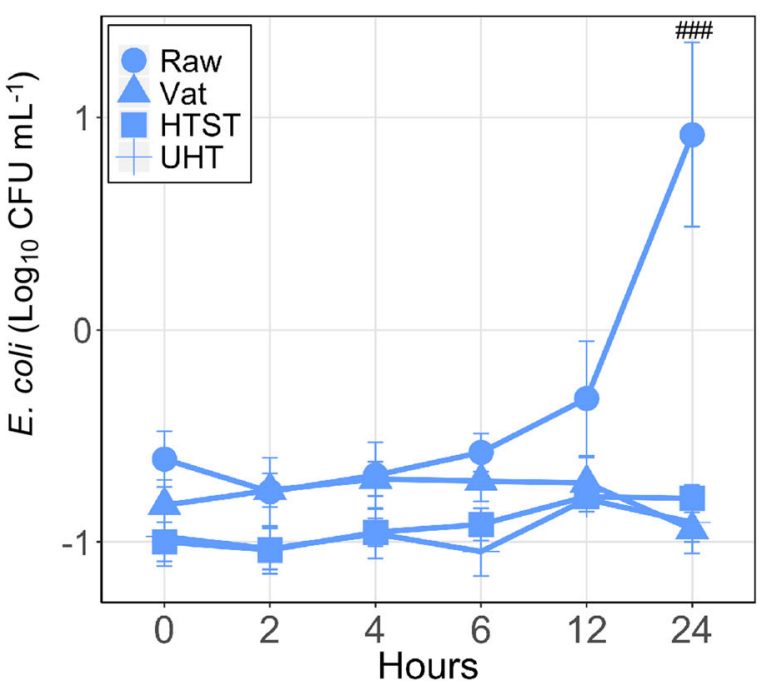

Fig. 1 Bacterial population dynamics of retail milk over $24 \mathrm{~h}$ room temperature (RT) incubation. a Bacterial populations in freshly purchased retail milk (without incubation). b Total aerobic bacteria; c Coliforms; $\mathbf{d}$ E. coli; populations during the RT incubation within $24 \mathrm{~h}$. A total of $1152 \mathrm{milk}$ samples were analyzed; Raw $(n=288)$, HTST $(n=432)$, Vat $(n=144)$, and UHT $(n=288)$. Solid and dashed horizontal lines represent the California milk threshold for aerobic bacteria $\left(<15,000\right.$ bacteria/mL) and coliforms ( $<10$ coliform $/ \mathrm{mL}$ ), respectively. ${ }^{\star} P<0.05,{ }^{\star \star} P<0.01$, and $\star \star \star P<0.001$ for comparison with raw milk of the same bacterial type. ${ }^{\#} P<0.05$, ${ }^{\# \#} P<0.01$, and ${ }^{\# \#} P<0.001$ for comparison with start point $(0$ h) within each type of milk

incubation $(24 \mathrm{~h})$ in raw milk (LMM, $P<0.001)$, while its abundance remained relatively stable in the other three types of milk (LMM, $P>0.05$, Fig. 1d). In all cases, there was no measurable bacterial growth observed in UHT milk (LMM, $P>0.05$, Fig. 1).

Given that raw milk is a potential source of foodborne pathogens, retail milk samples in the present study were screened for Listeria spp., Salmonella enterica, and E. coli O157:H7. None were detected. Indeed, a much larger sample size would be needed for a pathogen prevalence study, which was outside the scope of this work. However, of the isolated E. coli strains $(n=95)$, $84.2 \%(n=80)$ possessed at least one antibiotic resistance phenotype, and $35.8 \%(n=34)$ were multidrug resistant $(\geq 2$ resistance phenotypes). Ceftazidime resistance was the most prevalent phenotype in this cohort $(n=57 ; 60 \%)$ followed by resistance to amoxicillin ( $n=24 ; 25.3 \%)$, tetracycline $(n=24 ; 25.3 \%)$, and streptomycin $(n=22 ; 23.2 \%)$ (Supplementary table 1$)$. Genome sequencing of one representative multidrug-resistant $E$. coli strain JXLQYF114666 indicated the presence of nine transferrable ARGs (aph(3")-Ib, aph(6)-Id, bla $a_{\mathrm{CMY}-2}$, 
bla $_{\mathrm{TEM}-1 \mathrm{~B}}, \operatorname{mdf}(A), \operatorname{cat} A 2, \operatorname{sul} 2$, tet(B), and $\left.d f r A 14\right)$ conferring resistance to seven classes of medically important antibiotics (Supplementary table 2). The $b l a_{\mathrm{CMY}-2}$ gene, known to confer high-level ceftazidime resistance [25], appeared to reside on an IncI1 ST12 plasmid in JXLQYF114666. Conjugation assays demonstrated ceftazidime-resistance was successfully transferred to azide-resistant $E$. coli strain J53 and ceftazidimesusceptible Pseudomonas aeruginosa strain UCDDAM001 at frequencies of $2.8 \pm 0.35$ (mean \pm s.d.) $\times$ $10^{-4}$ and $6 \pm 1.44 \times 10^{-7}$ cells per recipient, respectively. In summary, bacterial populations in retail milk remained stable at refrigerated temperatures and did not contain known pathogens; however, RT incubation increased bacteria beyond state standards in raw and Vat-pasteurized milk and, even at cold temperatures, contained $E$. coli strains harboring a ceftazidime resistance gene which was transferrable.

\section{The dynamics of the retail milk microbiome in California during $4^{\circ} \mathrm{C}$ and $\mathrm{RT}$ incubations}

The bovine raw milk microbiota has been relatively wellstudied on farms $[17,18]$, in tanker trucks, and in processing facilities [19], but the microbiome of retail raw and pasteurized milk, remain elusive. To address this gap, 16S rRNA gene sequencing was used to systematically characterize the microbiota of California retail milk. As expected due to differences in live bacterial populations, we obtained different numbers of reads across types of milk, in which raw (median 6062; interquartile range (IQR), 31,578) and Vat milk (median 1678; IQR, 40,718 ) had a similar high amount of sequences per sample followed by HTST (median 662; IQR, 2683) and UHT (median 264; IQR, 1395) milk. Sequencing quality did not vary systematically across types of retail milk in California (and raw milk across states) (Kruskal-Wallis, $P=0.3$; Supplementary figure $2 \mathrm{c} \& \mathrm{~d}$ ).

Overall, retail milk of different processing types possessed varied microbiota structure (Bray-Curtis, PERMANOVA test by adonis2; $P=0.04$ ), in which HTST and UHT samples clustered in independent groups while raw and vat milk overlapped (Fig. 2a). Raw, Vat, and UHT milk samples indicated comparable alpha diversity, as measured by both Shannon index and Faith's phylogenetic diversity (PD) which remained relatively stable throughout the RT incubation (LMM, $P>0.05$, Fig. $2 \mathrm{~b}$ and c). HTST milk microbiota had the highest diversity (LMM, $P<$ 0.001 for both Shannon index and PD, Fig. 2b and c). This is consistent with the fact that HTST milk commonly comes from multiple dairies and bacteria that remain after heat-treatment are likely also diverse [26, 27]. Interestingly, the diversity estimated in HTST milk fluctuated over the RT incubation, during which both alpha diversities exhibited decreases at $4 \mathrm{~h}$ and $24 \mathrm{~h}$ (LMM, $P<0.01$,
Fig. $2 \mathrm{~b}$ and c). In addition, we likely underestimated the alpha diversity of HTST milk as the subsampling depth of 200 reads was not able to capture all of its observed amplicon sequence variants (ASVs) (Supplementary figure 2b).

The microbiota variances were further investigated by examining the taxonomic composition. Pseudomonadaceae was dominant in Raw (> 90\%; averaged relative abundance), Vat (> 70\%), and UHT (> 45\%) milks, while Streptococcaceae was more prevalent in HTST milk samples (Fig. 2d). The dominance of Pseudomonadaceae is consistent with lower temperature creating a selective advantage for psychrotolerant Pseudomonas spp. [28, 29]. Similar differences in microbiota were observed in retail milk kept in the cold environment, but the dynamic changes of alpha diversity were attenuated in HTST milk over the incubation compared to its dramatic change during RT incubation (Supplementary figure 3). Taken together, retail milk in California that underwent different processing and pasteurization procedures possessed distinct microbiomes. In addition, while viable bacterial populations measured in raw milk experienced a dramatic increase once incubated at RT, the relative abundance of the various taxa of raw milk, as observed by $16 \mathrm{~S}$ amplicon sequencing, remained stable over the same incubation.

\section{The antibiotic resistome of California retail milk during RT incubations}

To gain a deeper understanding of the milk resistome, shotgun metagenomic sequencing of DNA extracted from selected milk samples from California was conducted, garnering $109 \mathrm{~Gb}$ of sequencing data from 13 raw and 11 HTST milk microbiomes, with 6.5 (median; IQR, 2) million 150 bp paired-end (PE) reads per sample. Vat milk, of which the microbiota overlapped with raw milk (Fig. 2a), and UHT milk, in which no detectable live bacteria were observed (Fig. 1), were excluded from this analysis. Sequencing depth and quality did not vary significantly across types of milk on HiSeq 4000 (Supplementary figure. $4 \mathrm{a} \& \mathrm{~b}$ ).

ARGs were undetected in both HTST and raw milk samples at the first timepoint ( 0 h; Fig. 3a); however, the $24 \mathrm{~h}$ RT-incubation dramatically increased the measurable ARGs in raw milk microbiomes by comparison to HTST milk (Wilcoxon rank-sum test, $P=0.02$, Fig. 3a). Specifically, ARGs were observed in all incubated raw milks but the presence of ARGs only occurred in a single HTST sample (Fig. 3a). Leveraging a much higher sequencing depth with NovaSeq S4, we were able to detect ARGs in raw milks without incubation, and in both sequencing runs (i.e., HiSeq and NovaSeq), ARGs were significantly enriched via incubation (Wilcoxon signedrank test, $P=0.003$, Fig. 3b). In total, 49 ARGs 

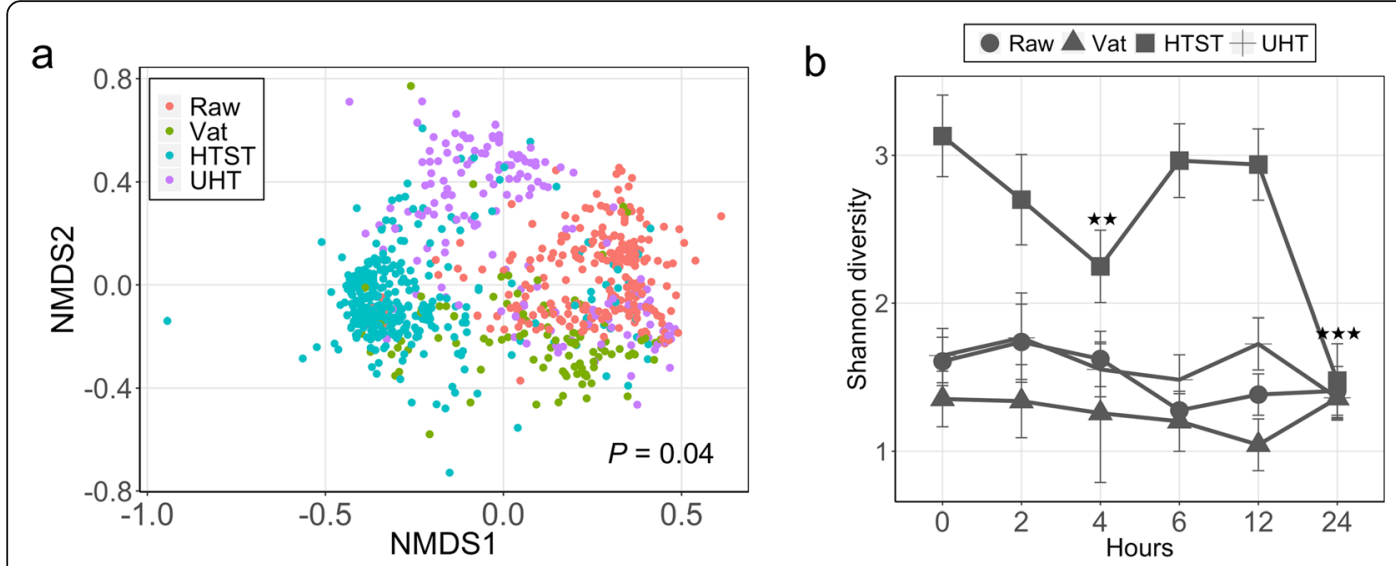

C

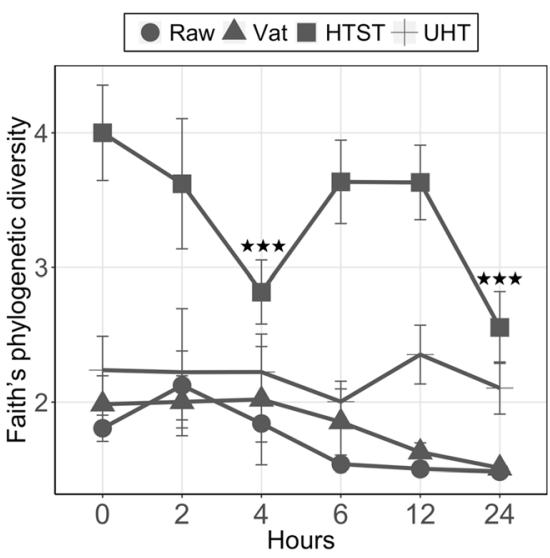

d

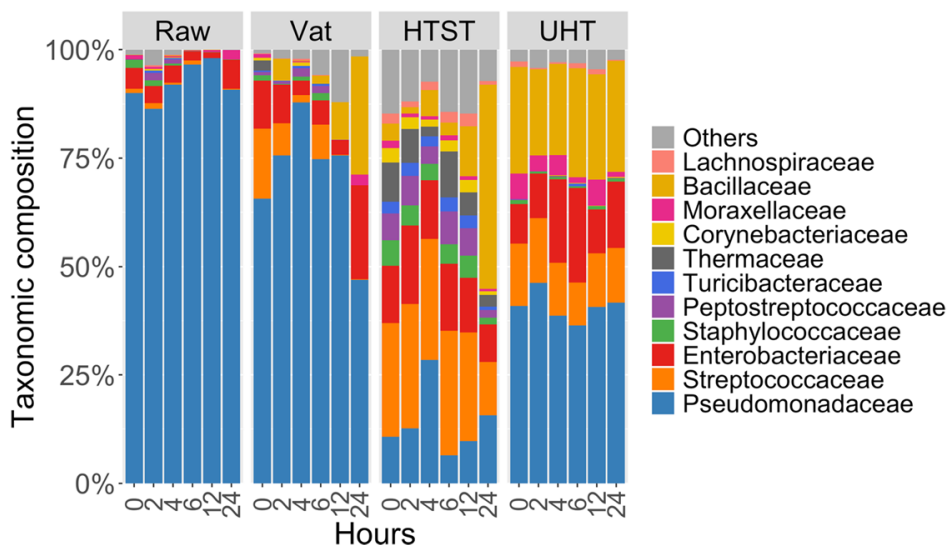

Fig. 2 The microbiota profiles of retail milk over room temperature incubations. a NMDS of retail milk samples based on Bray-Curtis ( $k=3$; stress $=0.15$; linear fit, $R^{2}=0.76$; non-metric fit, $R^{2}=0.96$ ). All 902 samples, after excluding low sequencing read milks (Raw $=270 ; \mathrm{Vat}=108 ; \mathrm{HTST}=$ 347; UHT $=177$ ), were included in this analysis. b Alpha diversity as measured by Shannon index in retail milk over RT incubation. c Alpha diversity as measured by Faith's phylogenetic diversity (PD) in retail milk over RT incubation. $\mathbf{d}$ Bar plot depicting the relative abundance of bacterial families over time; bacterial families which has a relative abundance less than $1 \%$ were grouped into "Others". ${ }^{\star \star} P<0.01$, and ${ }^{\star \star \star} P<$ 0.001 for comparison with start point $(0 \mathrm{~h})$ in HTST milk

belonging to 15 ARG groups, representing 7 antibiotic resistance mechanisms were found in California retail raw milk samples (Supplementary Data 1). These ARGs were predicted to confer resistance to 4 classes of antibiotics in a normalized abundance (hereafter referred to as abundance) ranging from 0 to 0.66 copies of ARG per $16 \mathrm{~S}$ rRNA gene in each sample (Fig. 3b). RT incubation significantly enriched ARGs belonging to all 4 classes of antibiotics (i.e., multidrug resistance, aminoglycosides, beta-lactams, and tetracyclines) within $24 \mathrm{~h}$ (Wilcoxon signed-rank test, $P<0.05$, FDR correction for multiple comparison, Fig. 3b).

Metagenomic assembly was employed to track the bacterial host of the observed ARGs [30]. Overall, we obtained 18, 940 (median; IQR, 14,579) contigs per sample, and the majority of ARG-containing reads (> 99\%) were successfully aligned to assembled contigs (Supplementary figure 5a and b). Importantly, most observed ARGs (62-80\%) were assigned a bacterial taxonomy at the family level (Supplementary figure $5 \mathrm{c}$ and d). Specifically, nine known bacterial families were predicted to host these ARGs, with Pseudomonadaceae harboring the highest number of unique ARGs (36) followed by Enterobacteriaceae (28), Yersiniaceae (14), and Moraxellaceae (8) (Fig. 3c; Supplementary Data 2). Therefore, retail raw milk in California was clearly a source of ARGs conferring resistance to 4 classes of medically important antibiotics; raw-milk-borne ARGs were readily amplified during RT-incubation and were mostly from Pseudomonadaceae, Enterobacteriaceae, and Yersiniaceae.

\section{The geographical variances of antibiotic resistome in retail raw milk across states}

Given that milk microbes could originate from animal skin, feces, and the local environment [31], raw milk samples from different geographical locations likely possess a regional-specific resistome [32]. To assess such variances 


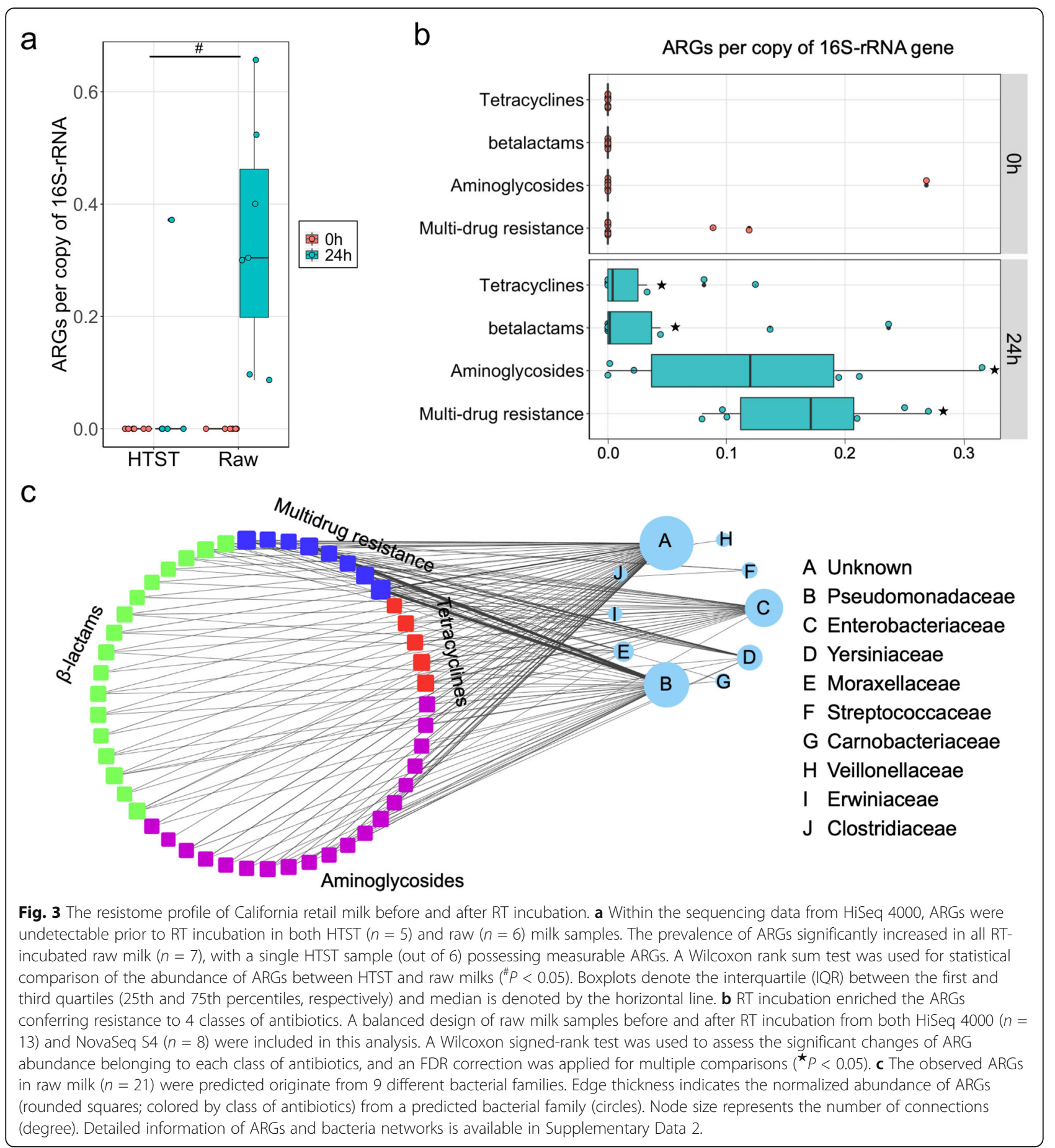

in the resistome of retail raw milk, a separate set of samples collected across the USA were subjected to shotgun metagenomic sequencing on the NovaSeq S4 platform. We obtained $589 \mathrm{~Gb}$ of sequencing data with 20 retail raw milk microbiomes from 4 states, approximately 40 (median; IQR, 5.9) million reads ( $150 \mathrm{bp}$ PE) per sample. Consistent with previous observations, sequencing depth and quality remained comparable in raw milk samples across states (Supplementary figure 4c \& d). For all shotgun metagenomic sequencing involved in this study (i.e., HiSeq and NovaSeq), we obtained sufficient sequencing depth to capture the bacterial species (profiled by Kraken2) and ARGs (identified by MEGARes) in retail milk samples (Supplementary figure 6). 
While raw milk samples from different geographic locations had varied abundance of ARGs (Kruskal-Wallis, $P=0.34$, Fig. 4a), the diversity of ARGs remained comparable (Kruskal-Wallis, $P=0.21$, Fig. $4 \mathrm{~b}$ ). Overall, we observed distinct resistome structure in raw milk from different states (Bray-Curtis, PERMANOVA test by adonis2; $P=0.002$, Fig. 4c). Within the cohort of 4 distinct sampling areas, 176 unique ARGs were identified that confer resistance to 12 classes of antibiotics (Fig. 4d; Supplementary Data 1 and Data 3). ARGs were observed in 2 (out of 4) raw milk samples from Arizona, in which the ARG-containing raw milk samples resembled the resistome structure to those in California (Fig. 4c and d). In these samples, resistomes were dominated by ARGs in "multidrug resistances" and aminoglycosides classes (Fig. 4d). Raw milk samples from South Carolina and Idaho shared similarities in resistome content. In both states, "multidrug resistance" was the prominent class of ARGs, and ARGs conferring resistance to beta-lactams were more prevalent than observed in Arizona and California (Fig. 4d). Tetracyclines-related ARGs were more abundant in samples from South Carolina and ARGs to trimethoprim were more frequently observed in raw milk samples from Idaho (Fig. 4d). In general, the differences observed in resistomes of raw milk can be largely explained by variances observed in milk microbiota (Fig. 4e and Supplementary figure 7). Specifically, there were 123 different ARGs detected in raw milks from South Carolina belonging to 15 bacterial families, 43 ARGs observed in raw milks from Idaho belonging to 15 bacterial families, and 15 unique ARGs originating from 3 bacterial families observed in raw milk samples from Arizona (Supplementary figure 8, 9 and 10; Supplementary Data 2). In summary, retail raw milk samples taken through RT
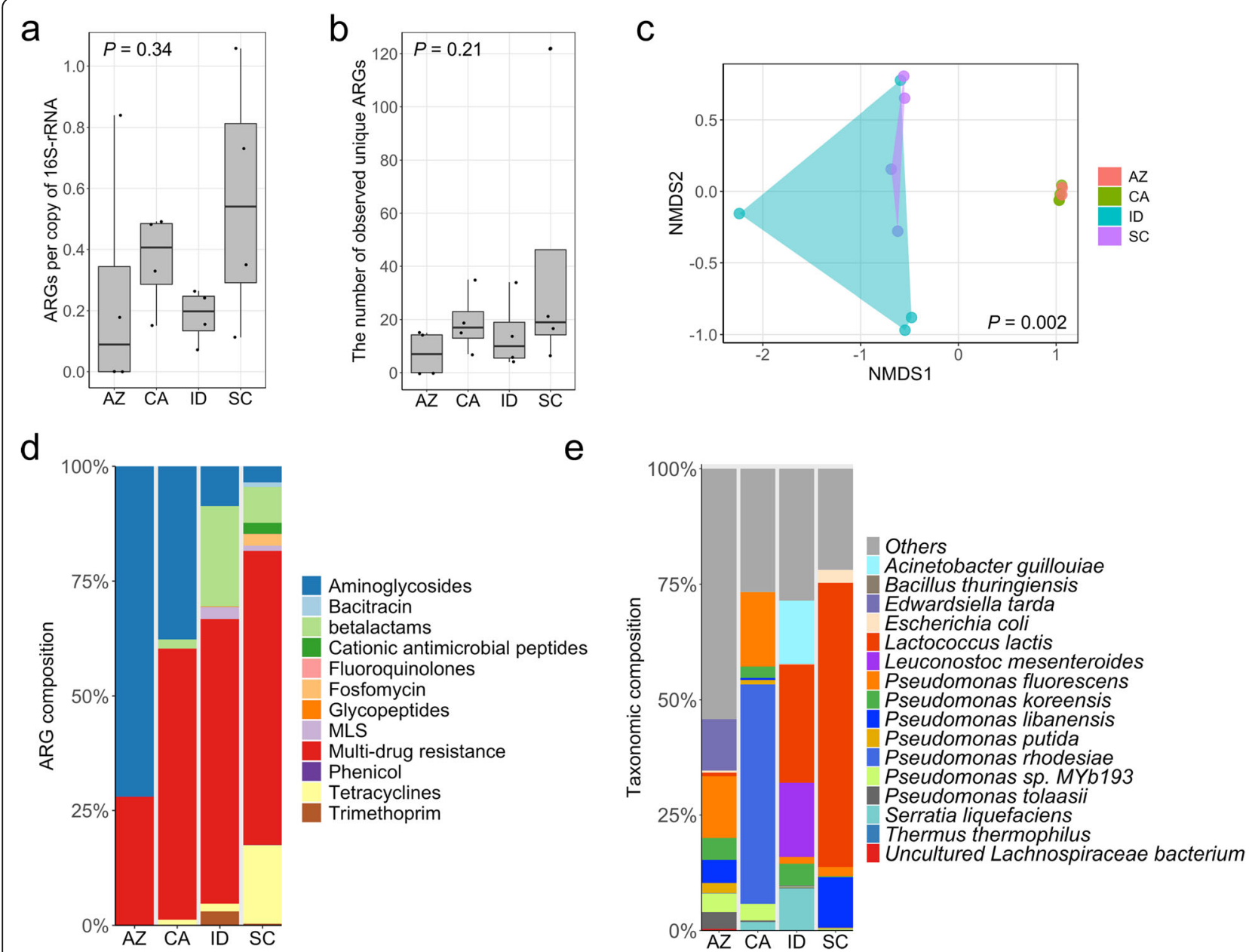

Fig. 4 Geographical variance of raw milk resistomes in the USA. a The total normalized abundance of ARGs in raw milk samples (NovaSeq S4; $n=$ 16) from different states. b The number of observed unique ARGs in raw milk samples $(n=16)$ from different states. $\mathbf{c}$ NMDS of raw milk resistome based on a Bray-Curtis dissimilarity calculation ( $k=2$; stress $=0.04$; linear fit, $R^{2}=0.99$; non-metric fit, $R^{2}=0.99$ ). Polygons were applied to raw milk samples collected from the same area. $\mathbf{d}$ Relative abundance of ARGs by class of antibiotics per sample. e Relative abundance of bacterial genus per raw milk sample across states. A Kruskal-Wallis test was implemented to assess the statistical differences of normalized abundance and richness across milks 
incubations were found to harbor ARGs conferring resistance to clinically relevant antibiotics; however, the type of ARGs differed by region.

\section{Discussion}

Raw milk is commonly consumed worldwide [12, 22]. In the United States, raw milk is often promoted for various nutritional and protective benefits. Consumption of raw milk as a general practice has been criticized due to the concern over contamination by foodborne pathogens [7-11]. The increasing prevalence of antibiotic resistance (AMR) is a global concern [33, 34], and the role of raw milk in the dissemination of AMR is unclear. To address this knowledge gap, we implemented an integrated approach employing culture-omics and high-throughput sequencing to assess the dynamic changes of microbiome and resistome in raw milk over incubations as well as their difference from pasteurized retail milk. Our results indicate that raw milk is a clear source of ARGs, which are readily enriched during RT-incubations, and the antibiotic resistome varies significantly in raw milk across states.

The microbial and ARG content of clabber milk-raw milk incubated at room temperature for several dayslikely varies by different milk sources, varied incubation time (1-5 days) and seasonally dependent room temperatures. However, the results presented here suggest that spontaneous fermentation does not grow beneficial lactic acid bacteria and instead, enrichment of ARGs occurred even within a short period of RT incubation. In addition to ARGs enriched due to intentional RT fermentation, proper cold-chain maintenance can fail during transportation from the raw milk producer to the consumer or in the home of the consumer, and therefore inadvertent short-term RT incubations can also happen. Such incubation likely enriches populations of bacteria in milk which in turn contributes to a modified resistome with elevated prevalence of ARGs. A better understanding the diversity of ARG content as well as the biogeography, health risk associations and methods to reduce this ARG reservoir, is clearly warranted.

Our findings also have implications for low-income countries, where consumption of unpasteurized dairy products is common $[35,36]$. One recent study evaluated the risk factors associated with carriage of antibiotic-resistant $E$. coli from people in northern Tanzania, and direct microbial transmission in raw milk was found to be the primary predictor of the prevalence of AMR [12], highlighting the role of raw milk in maintaining reservoirs of ARGs and transmitting antibiotic resistance.

While comprehensive, our findings have limitations. In light of the low-biomass nature of milk samples, the inferred microbial ecology from high-throughput sequencing is often mixed with various contaminants [37]. We employed a relatively stringent data filtration (excluded samples with less than 200 reads) in our $16 \mathrm{~S}$ rRNA gene sequencing dataset to reduce false positives. As expected, in the removed milk samples $(n=395)$, a large proportion (median 66.8\%; IQR, 64.9\%) of the microbiome were composed of shared ASVs with extraction controls, indicating potential DNA contaminants (Supplementary figure 2a). It is therefore possible that we underestimated true positives given low-sequencing reads may have been artificially excluded. Also, while metagenomic assembly offered us a unique opportunity to connect ARGs to a bacterial host [30], there were ARGs not assigned to any known bacterial families, which may be explained by the presence of chimeric contigs, and limitations of databases or taxonomy assignment software. Further, to rule out potential falsepositive identification of ARGs which require single nucleotide changes to confer resistance, we implemented RGI [38]. Only ARGs which survived this confirmation were reported in this study. This conservative approach may also underestimate the diversity of ARGs (i.e., increases the rate of false negatives) present in retail milk if the short sequencing reads did not capture the SNP required to confer resistance [39].

In summary, our findings suggest that retail raw milk has a higher prevalence of ARGs than pasteurized milk, an effect amplified by RT incubation. Unlike the implied dominance of "beneficial" lactic acid bacteria in unpasteurized milk [40, 41], retail raw milk microbiota varied in samples from distinct geographical locations, possessed few lactic acid bacteria, and were frequently dominated with microbes within the family Pseudomonadaceae. Our findings suggest that retail raw milk is a clear source of antibiotic-resistant bacteria and ARGs. This potential public health hazard appears to be more prevalent than specific pathogens with documented presence in retail samples across brands and regions of the USA. The public health and medical communities should continue to inform consumers of the microbial food safety risks from consumption of raw milk, and the increased risk from temperature abuse.

\section{Conclusion}

Employing a nation-wide retail milk sampling, we systematically studied the raw and pasteurized milk microbiota and antibiotic resistome. Raw milk microbiota and resistomes differ across geographical locations, and despite commonly advertised probiotic effects, raw milk possessed a limited component of lactic acid bacteria and is frequently dominated with Pseudomonadaceae. Compared to pasteurized milk, raw milk has a distinct microbiota with a higher abundance of viable bacteria 
containing antimicrobial resistance genes, both of which are amplified by spontaneous fermentation at room temperature. This work indicates that raw milk consumption poses an additional risk to consumers through transfer of antimicrobial resistance genes.

\section{Materials and methods}

Retail milk sampling, experimental design, and DNA extraction

The initial retail milk sampling occurred between March and August 2017 from grocery stores in California. A total of eight milk brands including ultra-pasteurized milk (UHT; $280-300^{\circ} \mathrm{F}, 2-6 \mathrm{~s} ; n=2$ brands), HTST pasteurized milk (high-temperature short-time, HTST; 161$165^{\circ} \mathrm{F}, 15-20 \mathrm{~s} ; n=3$ brands), vat pasteurized milk (Vat; $145^{\circ} \mathrm{F}, 30 \mathrm{~min} ; n=1$ brand), and unpasteurized milk (raw milk, Raw, $n=2$ brands) were examined in this study. All milk recruited via the initial sampling was whole milk which is certified as organic and rBST free (Supplementary table 3). Samples were collected from all brands of milk through eight independent purchases (biological replicates). For each purchase, the samples were aliquoted into three $15 \mathrm{~mL}$ tubes with $10 \mathrm{~mL}$ each (technical replicates). At $4{ }^{\circ} \mathrm{C}$, milk samples were incubated for $0,2,4,6$, and $24 \mathrm{~h}$; at $23^{\circ} \mathrm{C}$, milks experienced incubations for $0,2,4,6,12$, and $24 \mathrm{~h}$. Consequently, after incubation, a total of 1920 milk samples were obtained in California for analysis (Table 1).
To assess the geographical variance, a separate sampling of raw milk occurred between October 2018 and February 2019 in 4 other states including Idaho, Arizona, South Carolina, and Maine. Sampling states were chosen based on the availability of raw milk in retail stores [42] to maximize the geographical distribution of milk. At each state, two brands of raw milk produced from two different dairy farms were purchased at least twice from retail stores (Table 1). All samples collected were whole, non-homogenized milk, which are certified as organic and rBST free. Purchased raw milk was immediately aliquoted into $15 \mathrm{~mL}$ tubes, and half of the subsequent milk samples were directly placed in the freezer $\left(-20^{\circ} \mathrm{C}\right)$, and the remaining were incubated at RT for $24 \mathrm{~h}$ and then were stored at $-20^{\circ} \mathrm{C}$. Upon completion of sampling, a total of 114 samples were delivered on dry ice for analysis (Table 1).

For all the collected samples, approximately $2 \mathrm{~mL}$ vortexed milk was centrifuged at $10,000 \times g$ for $10 \mathrm{~min}\left(4^{\circ} \mathrm{C}\right)$ to separate cells and fat from whey [43]. The supernatant and the fat layer were removed, and the pellet was kept frozen $\left(-20^{\circ} \mathrm{C}\right)[30,43]$ until DNA extraction with a ZR Fecal DNA MiniPrep kit (ZYMO, Irvine, CA, USA).

\section{Quantification of total aerobic bacteria, coliform, and $E$. coli in retail milk}

In the California cohort, at $23^{\circ} \mathrm{C}$, we collected a total of 1152 samples with 144 samples per milk brand, and we obtained 960 milk samples from the $4{ }^{\circ} \mathrm{C}$ incubation with 120 samples per milk brand. At each temperature for a

Table 1 Sampling scheme and experimental design

\begin{tabular}{|c|c|c|c|c|c|c|c|c|c|}
\hline $\begin{array}{l}\text { Sampling } \\
\text { states }\end{array}$ & $\begin{array}{l}\text { Milk } \\
\text { type }\end{array}$ & $\begin{array}{l}\text { Incubation } \\
\text { temperature }\end{array}$ & Incubation time & $\begin{array}{l}\text { No. of milk } \\
\text { brands }\end{array}$ & $\begin{array}{l}\text { No. of } \\
\text { samples }\end{array}$ & $\begin{array}{l}\text { Bacterial } \\
\text { plating }\end{array}$ & $16 S^{a}$ & $\begin{array}{l}\mathrm{SMS}^{\mathrm{b}}(\mathrm{HiSeq} \\
4000)\end{array}$ & $\begin{array}{l}\text { SMS }^{b} \\
\text { (NovaSeq S4) }\end{array}$ \\
\hline \multirow[t]{4}{*}{ California } & Raw & $4^{\circ} \mathrm{C}, 23^{\circ} \mathrm{C}$ & $\begin{array}{l}0 \mathrm{~h}, 2 \mathrm{~h}, 4 \mathrm{~h}, 6 \mathrm{~h}, \\
12 \mathrm{~h}^{\mathrm{c}}, 24 \mathrm{~h}\end{array}$ & 2 & 480 & $\checkmark$ & $\checkmark$ & $\checkmark(n=13)$ & $\checkmark(n=8)$ \\
\hline & Vat & $4^{\circ} \mathrm{C}, 23^{\circ} \mathrm{C}$ & $\begin{array}{l}0 \mathrm{~h}, 2 \mathrm{~h}, 4 \mathrm{~h}, 6 \mathrm{~h}, 12 \mathrm{~h}, \\
24 \mathrm{~h}\end{array}$ & 1 & 240 & $\checkmark$ & $\checkmark$ & $x$ & $x$ \\
\hline & HTST & $4^{\circ} \mathrm{C}, 23^{\circ} \mathrm{C}$ & $\begin{array}{l}0 \mathrm{~h}, 2 \mathrm{~h}, 4 \mathrm{~h}, 6 \mathrm{~h}, 12 \mathrm{~h}, \\
24 \mathrm{~h}\end{array}$ & 3 & 720 & $\checkmark$ & $\checkmark$ & $\checkmark(n=11)$ & $x$ \\
\hline & UHT & $4^{\circ} \mathrm{C}, 23^{\circ} \mathrm{C}$ & $\begin{array}{l}0 \mathrm{~h}, 2 \mathrm{~h}, 4 \mathrm{~h}, 6 \mathrm{~h}, 12 \mathrm{~h}, \\
24 \mathrm{~h}\end{array}$ & 2 & 480 & $\checkmark$ & $\checkmark$ & $x$ & $x$ \\
\hline $\begin{array}{l}\text { South } \\
\text { Carolina }\end{array}$ & Raw & $23^{\circ} \mathrm{C}$ & $0 \mathrm{~h}, 24 \mathrm{~h}$ & 2 & 24 & $x$ & $\checkmark$ & $x$ & $\checkmark(n=4)$ \\
\hline Arizona & Raw & $23^{\circ} \mathrm{C}$ & $0 \mathrm{~h}, 24 \mathrm{~h}$ & 2 & 30 & $x$ & $\checkmark$ & $x$ & $\checkmark(n=4)$ \\
\hline Idaho & Raw & $23^{\circ} \mathrm{C}$ & $0 \mathrm{~h}, 24 \mathrm{~h}$ & 2 & 36 & $x$ & $\checkmark$ & $x$ & $\checkmark(n=4)$ \\
\hline Maine & Raw & $23^{\circ} \mathrm{C}$ & $\mathrm{Oh}$ & 2 & 24 & $x$ & $\checkmark$ & $x$ & $x$ \\
\hline
\end{tabular}

For samples from California, the incubations at different temperature shared a single start point $(0 \mathrm{~h})$. $\checkmark$ indicates all the collected samples were subjected to a type of analysis unless a number is specified, while $\times$ represents the corresponding analysis was not performed. For the HiSeq 4000 run, 13 raw milk samples $(6$ samples were collected before any incubations and the remaining 7 samples experienced a $24 \mathrm{~h}$ incubation at $\left.23^{\circ} \mathrm{C}\right)$ and $11 \mathrm{HTST}$ samples $(5$ samples were recruited before incubation and the other 6 were incubated at $23^{\circ} \mathrm{C}$ for $24 \mathrm{~h}$ ) were included to determine the resistome variances between milks as well as before and after room temperature incubation. Unequal number of metagenomes were obtained (i.e., 13, 11) as a result of unexpected sequencing failure of certain DNA samples. In the NovaSeq S4 run, 4 raw milk samples after a $24 \mathrm{~h}$ incubation at $23^{\circ} \mathrm{C}$ from each state (California, South Carolina, Arizona, and Idaho) were used to assess the geographical variance of milk resistomes, and another 4 samples before incubation from the California cohort were included to validate results between sequencing platforms/runs

a 165 rRNA gene sequencing

${ }^{b}$ Shotgun metagenomic sequencing

${ }^{\mathrm{c} S}$ Samples from 12 -h incubation under $4{ }^{\circ} \mathrm{C}$ were skipped for bacterial plating 
given incubation time, $1 \mathrm{~mL}$ milk samples (serial dilutions were applied when appropriate) were used to culture onto $3 \mathrm{M}$ Petrifilm plate $(3 \mathrm{M}$, Maplewood, $\mathrm{MN}$, USA) at $37^{\circ} \mathrm{C}$ incubator for $24 \mathrm{~h}$ to quantify the total aerobic bacteria populations, coliform, and E. coli. All numbers were recorded and transformed into $\log _{10} \mathrm{CFU}$ per $\mathrm{mL}$ of milk prior to downstream analysis. Zero values were adjusted with the analytical detection limit of our assays, $6.6 \mathrm{CFU} / \mathrm{mL}$ for total aerobic counts and $0.33 \mathrm{CFU} / \mathrm{mL}$ for both coliform and $E$. coli, following the formula "substitution $=\log (\operatorname{RAND}() \times$ (detection limit))" in Excel (Microsoft Corp., Redmond, WA). Mean values were calculated from three technical replicates, representing the biological milk sample, for statistical analyses. A Kruskal-Wallis test was used to assess the statistical difference of bacterial populations in different types of milk prior to incubations, and a Dunn test in FSA package (0.8.24) was used for multiple comparisons [false discovery rate (FDR) $p$ value adjustments]. A linear mixed model (LMM) from the lme4 package (version 1.1.21) was implemented to test for associations between the incubation time and the bacterial population in each type of milk. The glht function in multcomp package (version 1.4.10) in combination with the $l s m$ function in lsmeans package (version 2.30.0) was used for intra- and intergroup pairwise comparisons ( $p$ values were adjusted with a single-step method).

\section{E. coli isolation and antibiotic susceptibility testing}

In the course of bacterial quantification, if present, 1-2 $E$. coli isolates were collected randomly per milk sample which resulted in a total of 95 presumptive E. coli isolates from California. The bacterial species identities were further confirmed by examining the entire $16 \mathrm{~S}$ rRNA gene via Sanger sequencing [44]. All isolates were subjected to antibiotic susceptibility testing with a breakpoint assay [12]. Briefly, MacConkey agar was prepared with 16 clinically relevant antibiotics (Supplementary Table 1) of fixed concentration, which was guided by the Clinical and Laboratory Standards Institute minimum inhibitory concentrations for Enterobacteriaceae [45]. Genomic DNA of an E. coli strain with a multidrug resistance phenotype (Ampicillin-CeftazidimeChloramphenicol-Ciprofloxacin-Penicillin G-PiperacillinStreptomycin-Tetracycline), which was labeled as E. coli strain JXLQYF114666, was extracted using a DNeasy Blood \& Tissue Kit (Qiagen, Hilden, Germany) and was subsequently sequenced on an Illumina MiSeq platform (Reagent kit v2; 250 bp PE) at UC Davis DNA Technologies \& Expression Analysis Core. Genome sequencing reads were assembled into contigs using SPAdes (3.10.1) with default parameters. Assembled contigs were run through ResFinder (3.1, [46]) and PlasmidFinder (2.0, [47]) to assess the presence of acquired ARGs and plasmids in E. coli strain JXLQYF114666, respectively. The plasmid type of bla $_{\mathrm{CMY}-2}$-harboring contig $(53,836 \mathrm{bp})$ was characterized by using pMLST-2. 0[47].

\section{Conjugation experiments}

A conjugation assay [48] was performed to determine whether the $b l a_{\mathrm{CMY}-2}$ gene was present on a conjugative plasmid, with E. coli strain JXLQYF114666 as the donor and azide-resistant E. coli J53 (ATCC BAA2731) and ceftazidime-susceptible $P$. aeruginosa strain UCDDAM001 as recipients. Briefly, separate cultures of donor and recipient were prepared aerobically overnight $\left(37^{\circ} \mathrm{C}, 220\right.$ r.p.m.) in LB broth. The following day, individual overnight cultures were inoculated into fresh $\mathrm{LB}$ (1:100) until an $\mathrm{OD}_{600 \mathrm{~nm}}$ of 0.6-0.8. Then, equal amount of donor and recipient cultures $(2 \mathrm{~mL})$ were centrifuged for $5 \mathrm{~min}$ at $10,000 \times g$, and the pellets were resuspended in $50 \mu \mathrm{L} \mathrm{LB}$ broth and mixed. The resultant suspension was spread onto a LB agar plate and incubated stationary overnight at $37^{\circ} \mathrm{C}$. E. coli transconjugants were selected on Mueller-Hinton agar plates containing ceftazidime $(16 \mu \mathrm{g} / \mathrm{mL})$ and sodium azide $(150 \mu \mathrm{g} / \mathrm{mL})$, and $P$. aeruginosa transconjugants were selected on Pseudomonas isolation agar (Hardy Diagnostics, Santa Maria, CA) with ceftazidime $(16 \mu \mathrm{g} / \mathrm{mL})$. The presence of $b l a_{\mathrm{CMY}-2}$ gene was confirmed by PCR [49] and sequencing in transconjugants. Transfer frequencies were calculated as the number of transconjugants obtained per input recipient cell.

\section{S rRNA gene sequencing and data analysis}

Duplicate DNA samples (out of three replicates) from the incubation assay in California $(n=1,280)$, together with raw milk DNA from other states $(n=114)$ and extraction controls (i.e., blanks without any biological samples added; $n=37$ ) were prepared for $16 \mathrm{~S}$ rRNA gene sequencing as previously described [30]. Briefly, the forward F515 primer which includes an eight-nucleotide barcode unique to each sample and a two-nucleotide linker sequence ( $5^{\prime}$ NNNNNNNNGTGTGCCAGCMGCCGCGGTAA-3') and the reverse R806 primer (5'-GGACTACH VGGGTWTCTAAT-3') were used to amplify the V4 region of the $16 \mathrm{~S}$ rRNA gene. PCR reactions were carried out in triplicate in a $15-\mu \mathrm{L}$ reaction containing $1 \mathrm{X}$ GoTaq Green Mastermix (Promega, Madison, WI, USA), $1 \mathrm{mM}$ $\mathrm{MgCl} 2$ and 2 pmol of each primer. The PCR amplification conditions included an initial denaturation step of $2 \mathrm{~min}$ at $94^{\circ} \mathrm{C}$, followed by 25 cycles of $94{ }^{\circ} \mathrm{C}$ for $45 \mathrm{~s}, 50^{\circ} \mathrm{C}$ for $60 \mathrm{~s}$, and $72^{\circ} \mathrm{C}$ for $90 \mathrm{~s}$, followed by a final extension step at $72{ }^{\circ} \mathrm{C}$ for $10 \mathrm{~min}$. Triplicate reactions were combined and purified using a Qiagen PCR purification column and submitted to the DNA Technologies \& Expression Analysis Core at UC Davis for sequencing on an Illumina MiSeq platform (Reagent kit v2; 250 bp PE). 
Raw sequencing reads were demultiplexed by using the Sabre software (sabre pe) (https://github.com/ najoshi/sabre), and the sequencing quality was assessed by using FASTQC (version 0.11.9) per sequence [50]. In light of the number of sequences obtained from blank control samples (<138 reads/sample), samples with low sequencing read counts $(<200$ reads) were excluded, resulting in a total of 902 samples (Raw $=270$; Vat $=$ 108 ; HTST $=347$; UHT $=177$ ) for downstream analysis. In the remaining samples $(n=902)$, potential sequencing contaminants were further identified and removed using decontam (version 1.4.0; method = "prevalence") with the default probability threshold [51]. Applying the same filtration criteria, in other states, 97 raw milk samples $(\mathrm{AZ}=24 ; \mathrm{ID}=32 ; \mathrm{ME}=21$; $\mathrm{SC}=20$ ) with 7458 (median; IQR, 15,796) sequences survived for further analysis. Our data filtration excluded a total of 395 retail milk samples $(\mathrm{HTST}=146$; UHT $=137$; Raw $=69$; Vat = 39), in which $66.8 \%$ (median; IQR, 64.9\%) of sequencing reads represented shared ASVs with extraction controls (Supplementary figure 2a).

The remaining sequencing reads were then loaded into QIIME2 (version: 2019.1, [52]) (qiime tools import --type 'SampleData [PairedEndSequencesWithQuality]' --sourceformat PairedEndFastqManifestPhred33). The sequence quality control and feature table construction were performed using DADA2 [53] (qiime dada2 denoise-paired -p-trim-left-f 21 --p-trim-left-r 23 --p-trunc-len-f $242-$-ptrunc-len-r 250). The feature table was rarefied at the maximum sampling depth of 200 reads, and was used to calculate the alpha diversity as measured by Shannon index and Faith's phylogenetic diversity (qiime diversity core-metrics-phylogenetic). Our rarefaction curve analysis (qiime diversity alpha-rarefaction) indicated that a subsampling of 200 reads per sample was able to capture the majority of the observed ASVs in this cohort (Supplementary figure $2 \mathrm{~b}$ ). A linear mixed model (LMM) from the lme4 package [54] (version 1.1.21) was implemented to test for associations between the incubation time and the alpha diversity in each type of milk. The glht function in multcomp package [55] (version 1.4.10) in combination with the $l s m$ function in lsmeans package [56] (version 2.30.0) was used for intra- and intergroup pairwise comparisons ( $p$ values were adjusted with a single-step method). Beta diversity was examined with Bray-Curtis distance matrices based on a CSS [57] normalized feature table and was visualized using non-metric multidimensional scaling (NMDS) in $\mathrm{R}$ [58]. Differences in beta-diversity were tested using adonis2 (PERMANOVA test) in the vegan package [59] after checking for differences in dispersion using betadisper. Taxonomy was assigned using QIIME2 (qiime feature-classifier classify-sklearn) against the SILVA database (release 132, [60]).

\section{Shotgun metagenomic sequencing}

The initial metagenomic sequencing run with retail milk samples solely from California ( $\mathrm{raw}=13, \mathrm{HTST}=11$ ) was completed on an Illumina HiSeq 4000 platform and the second sequencing run with raw milk samples from 4 states $(n=20)$ was performed on an Illumina NovaSeq S4 platform (Table 1). Both sequencing libraries were prepared following the same procedure in the UC Berkeley Functional Genomics Laboratory (FGL) and were sequenced with the 150 paired-end reads strategy in the Vincent J. Coates Genomics Sequencing Laboratory at the University of California, Berkeley.

Briefly, each sample was sheared using the $150 \mathrm{bp}$ setting of the Diagenode Bioruptor, then purified and concentrated with the Qiagen Minelute cleanup kit. End repair, a tailing of DNA fragments, and adapter ligation were performed using the KAPA Hyper Prep library kit. Next, 9 cycles of indexing PCR were performed using the KAPA Hi-Fi Hotstart amplification kit. Cleanup and dual-SPRI size selection were completed using AMPure beads. Libraries were checked for quality on the AATI fragment analyzer.

Raw sequences were used to assess the sequencing quality by calculating the average quality score per sequence using FASTQC (version 0.11.9) [50]. To avoid host DNA contamination, BMTagger in bmtools (version 1) was used to remove reads aligning to the bovine genome (version UMD3.1) from all samples. The resulting reads were then trimmed using Trimmomatic (version 0.36) [61] and merged using FLASH (version 1.2.11) [62] prior to downstream analysis. Taxonomy profiling of metagenomes were performed using Kraken2 [63] to map against a custom database including RefSeq [64] and 4941 metagenome-assembled rumen genomes [65]. The relative abundance of the bacterial genus was estimated using Bracken [66].

\section{Antibiotic resistome analyses}

Merged sequencing reads were aligned to the ARG database MEGARes (version 1.0.1) [67] using BWA with default settings [68]. In the generated SAM formatted file, alignments tagged with "RequiresSNPconfirmation" were extracted which were further subjected to a secondary functional validation by using Resistance Gene Identifier (RGI) (version 5.1.0) with "Perfect" and "Strict" algorithms [38]. This secondary analysis is critical to rule out false-positive ARGs which often require single nucleotide mutations to confer resistance [69]. Sequencing reads did not survive the RGI-based confirmation were excluded from the SAM file, and the remaining alignments were then analyzed through ResistomeAnalyzer (-t 80 ; at least $80 \%$ of nucleotides in the reference sequence that were aligned to by at least one sequence read) to quantify ARGs (https://github.com/cdeanj/ 
resistomeanalyzer). This analysis outputs data into gene, group, mechanism, and class levels corresponding to the levels of the annotation in the database hierarchy [67], and the gene-level data (e.g., TEM-77, TEM-107, TEM73 , etc.) were used to calculate the ARG diversity. MEGARes (version 1.0.1) is a manually curated database that consists of a collection of 3824 ARGs with the reference sequences ranging in size from 211 to $4185 \mathrm{bp}$ [67]. The counts data were normalized with 16S rRNA gene by including the information of ARG sequence length and sequencing depth. Normalized ARG abundance was expressed as "copy of ARG per copy of 16S rRNA gene" as suggested by $\mathrm{Li}$ et al. [30, 70,71]. The number of reads mapping to $16 \mathrm{~S}$ rRNA bacterial gene was determined using METAXA2 (version 2.1.3) [72], and 1432 bp was used for calculations as the average length of $16 \mathrm{~S}$ rRNA gene. Differences in resistome structure across states based on Bray-Curtis distance measures were tested using adonis2 (PERMANOVA test) in the vegan package after checking for differences in dispersion using betadisper.

Metagenome assemblies were generated with trimmed but un-merged reads for each sample using MEGAHIT (version 1.0.6) with default parameters [73]. The assembled contigs were used to predict the bacterial origin of observed ARGs. Specifically, the ARG-aligned sequencing reads, which survived the RGI confirmation, were used to align to contigs with BWA-MEM [68], and contigs that contain ARG sequences were kept for taxonomic assignment. taxator-tk (version 1.3.3) [74], a software designed to perform taxonomic analysis of assembled metagenomes, was applied to predict the bacterial origin of contigs. In particular, we used taxator-tk with our custom database which includes both RefSeq [64] and 4941 rumen-related metagenome-assembled genomes [65] with parameters -a megan-lca -t 0.3 -e 0.01 to assign taxonomy of ARG-containing contigs at the family level. All networks were visualized using Cytoscape (version 3.7.2) [75].

\section{Supplementary information}

Supplementary information accompanies this paper at https://doi.org/10. 1186/s40168-020-00861-6.

Additional file 1: Supplementary Data 1. List of ARGs observed in milk samples from California.

Additional file 2: Supplementary Data 2. Data employed in all network analyses in this work.

Additional file 3: Supplementary Data 3. List of ARGs observed in raw milk from Arizona, Idaho, and South Carolina.

Additional file 4: Supplementary Table 1. Antibiotics and minimum inhibitory concentration used for the breakpoint assay. All $95 \mathrm{E}$. coli strains isolated from retail raw milk in California were subjected to the antibiotic susceptibility testing with a collection of 16 clinically relevant antibiotics.
Additional file 5: Supplementary Table 2. Antibiotic resistance genes detected from whole-genome sequencing of E. coli strain JXLQYF114666.

Additional file 6: Supplementary Table 3. Metadata of retail milk samples collected in California. This retail milk sampling occurred between March and August 2017 from grocery stores in California.

Additional file 7: Supplementary Figure 1. The bacterial population in retail milk over incubations at $4^{\circ} \mathrm{C}$. $\mathbf{a}$, Total aerobic bacteria $\mathbf{b}$, Coliform c, E. coli populations during the $4^{\circ} \mathrm{C}$ incubation within $24 \mathrm{~h}$. A total of 960 milk samples from California were analyzed; Raw $(n=240)$, HTST $(n=360)$, Vat $(n=120)$, and UHT ( $n=240)$. Solid and dashed horizontal lines (red) represent the California milk limit for aerobic bacteria $(<15,000$ bacteria/ $\mathrm{mL}$ ) and coliform ( $<10$ coliform $/ \mathrm{mL}$ ), respectively. A linear mixed model (LMM) from the Ime4 package (version 1.1.21) in $\mathrm{R}$ was implemented to test for associations between the incubation time and the bacterial population in each type of milk. $\star P<0.05$ for comparison with start point (0 hour) in raw milk.

Additional file 8: Supplementary Figure 2.The descriptive analysis of $16 \mathrm{~S}$ rRNA gene sequencing in retail milk. a, The relative abundance of 15 shared ASVs (with extraction controls) in excluded low-read milk samples $(n=395)$. Milk samples were ranked by sequencing depth. b, The rarefaction curve of observed ASVs across types of retail milk in California. The vertical orange line indicates the subsampling read depth for rarefied feature table. c, The distribution of sequencing reads by phred quality score in retail milk from California. $\mathbf{d}$, The distribution of sequencing reads by phred quality score in raw milk across states in the United States. A Kruskal-Wallis test was used to assess the statistical significance of sequencing quality variance.

Additional file 9: Supplementary Figure 3. The microbiota profiles of retail milk over $4^{\circ} \mathrm{C}$ incubations. a, alpha diversity as measured by Shannon index in retail milk over $4^{\circ} \mathrm{C}$ incubation. $\mathbf{b}$, alpha diversity as measured by Faith's phylogenetic diversity (PD) in retail milk over $4^{\circ} \mathrm{C}$ incubation. c, Bar plot depicting the relative abundance of bacterial families over time; bacterial families which has a relative abundance less than $1 \%$ were grouped into "Others". A linear mixed model (LMM) from the Ime4 package (version 1.1.21) was implemented to test for associations between the incubation time and the alpha diversity in each type of milk. $\star P<0.05$ for comparison with start point ( 0 hour) in HTST milk.

Additional file 10: Supplementary Figure 4. The descriptive analysis of shotgun metagenomic sequencing in retail milk. $\mathbf{a}$, The sequencing depth of HTST and raw milk samples in California sequenced via HiSeq. b. The distribution of sequencing reads by phred quality score in retail milk from California. c, The sequencing depth of raw milk samples sequenced via NovaSeq across states. d, The distribution of sequencing reads by phred quality score in raw milk across states in the United States. A Kruskal-Wallis test was used to assess the statistical significance of sequencing depth and quality variances.

Additional file 11: Supplementary Figure 5. Descriptive analyses of metagenomic assembly and taxonomic assignment of ARGs. All raw milk samples harboring ARGs ( $n=23$ ) were included in this analysis. $\mathbf{a}$, Boxplot depicting the distribution of number of metagenomic assembled contigs in raw milk across states. A Kruskal-Wallis test was used to assess the statistical significance of contigs between states. b. The percentage of ARGcontaining sequencing reads which were successfully aligned to metagenomic assembled contigs. c, The percentage of ARG-containing contigs assigned at the family level. $\mathbf{d}$, The percentage of ARG-containing reads assigned at the family level.

Additional file 12: Supplementary Figure 6. Rarefaction curves of taxonomic profiling (kraken 2) and resistome analysis (MEGARes) in retail milk. a, The rarefaction curve of kraken 2 observed bacterial species in raw milks samples $(n=16)$. Only raw milk samples sequenced via NovaSeq and used for taxonomic comparisons in Figure 4e were included in this analysis. b. The rarefaction curve of observed ARGs via MEGARes in retail milk across states. All retail milk samples harboring ARGs in this cohort ( $n=24$; Raw=23, HTST=1) were included in this analysis.

Additional file 13: Supplementary Figure 7. The microbiota of retail raw milk from five states in the United States. a, alpha diversity as measured by Shannon index in raw milk across states. b, alpha diversity 
as measured by Faith's phylogenetic diversity (PD) in raw milk across states. c, NMDS of raw milk samples based on Bray-Curtis ( $k=3$; stress = 0.17; Linear fit, R2=0.80; Non-metric fit, $R 2=0.97$ ). Subsampling to obtain equal sample size $(n=20)$ for each state was completed prior to performing the ordination analysis and PERMANOVA. The centroid of each ellipse represents the group mean, and the shape was defined by the covariance within each group. $\mathbf{d}$, Bar plot depicting the relative abundance of bacterial families across states; bacterial families which has a relative abundance less than $1 \%$ were grouped into "Others". e, Best taxonomic discriminators of retail raw milk microbiota across states ranked by random forest classifier (mean importance $>0.01$ ). ASVs were ranked by a random forest classifier available in the randomForest package (4.6.14) in R. $\mathbf{a}-\mathbf{b}$, A Kruskal-Wallis test was used to assess the statistical difference of alpha diversity in raw milk from different states, and a Dunn test in FSA package (0.8.24) was used for multiple comparisons [false discovery rate (FDR) $p$ value adjustments]. Different letters indicate statistically significant groups.

Additional file 14: Supplementary Figure 8. The predicted bacterial families of ARGs observed in raw milk from South Carolina. There were 123 ARGs originating from 15 bacterial families were detected in milk samples. Families harboring $<10$ individual ARGs were not labeled, and detailed information of ARGs and bacteria networks is available in Supplementary Data 2. Edge thickness indicates the normalized abundance of ARGs (rounded squares; colored by class of antibiotics) from a predicted bacterial family (circles). Node size represents the number of connections (degree).

Additional file 15: Supplementary Figure 9. The predicted bacterial families of ARGs observed in raw milk from Idaho. There were 43 ARGs originating from 15 bacterial families were detected in milk samples. Families harboring $<10$ individual ARGs were not labeled, and detailed information of ARGs and bacteria networks is available in Supplementary Data 2. Edge thickness indicates the normalized abundance of ARGs (rounded squares; colored by class of antibiotics) from a predicted bacterial family (circles). Node size represents the number of connections (degree).

Additional file 16: Supplementary Figure 10. The predicted bacterial families of ARGs observed in raw milk from Arizona. There were 15 ARGs originating from 3 bacterial families were detected in milk samples. Detailed information of ARGs and bacteria networks is available in Supplementary Data 2. Edge thickness indicates the normalized abundance of ARGs (rounded squares; colored by class of antibiotics) from a predicted bacterial family (circles). Node size represents the number of connections (degree).

\section{Acknowledgements}

We thank Peiman Aminabadi and Amlan Aggrawal (University of California, Davis) for technical assistance with raw milk quality testing. We thank Yifei Kang (Washington State University), Liang Zhang (Arizona State University), Yanlan Shi (University of South Carolina), Qingying Feng, Feng Yu, Diana Taft, Marjorie Hall for helpful discussions and guidance in samples collection. We thank Alice Yu, Karen Kalanetra, and Melanie Shojinaga for sequencing library preparation, DNA sequencing methodologies, and analysis. We would like to thank Bruce German for critical review and helpful discussions of the manuscript. This work used the Vincent J. Coates Genomics Sequencing Laboratory at UC Berkeley, supported by NIH S10 Instrumentation Grants S10RR029668 and S10RR027303.

\section{Authors' contributions}

$J L, M J R, D G L$, and DAM designed experiments; $J$ and $Y Z$ executed experiments; $J L$ and DGL analyzed the data. JL and DAM wrote the paper, with input from all authors. All authors read and approved the final manuscript.

\section{Funding}

This work has been supported by National Institutes of Health awards R01AT007079 and R01AT008759 and the Peter J. Shields Endowed Chair in Dairy Food Science. DGL is funded by the US Department of Agriculture (USDA) project 2032-51530-026-00-D. The USDA is an equal opportunity employer.

\section{Availability of data and materials}

Sequencing data generated from both amplicon and shotgun metagenomes in this study have been deposited with the NCBI SRA (PRJNA575106) and are publicly available. The genome sequences of E. coli strain JXLQYF114666 was submitted to JGI and is available under Ga0374221. Other data of this study are available from the authors upon reasonable request.

\section{Ethics approval and consent to participate}

Not applicable

\section{Consent for publication}

Not applicable

\section{Competing interests}

DAM is a co-founder of Evolve Biosystems, a company focused on dietbased manipulation of the gut microbiota and BCD Biosciences, a company focused on bioactive glycans. Neither Evolve Biosystems or BCD Biosciences had a role in the conceptualization, design, data collection, analysis, or preparation of this manuscript. MJR is a co-founder of the Real Raw Milk Facts website funded in part by MarlerClark-The Food Safety Law Firm, and has served as an objective expert witness for raw milk and food safety cases. MarlerClark had no role in the conceptualization, design, data collection, analysis, or preparation of this manuscript.

\section{Author details}

'Department of Food Science and Technology, Robert Mondavi Institute for Wine and Food Science, University of California, Davis, One Shields Ave, Davis, CA 95616, USA. ${ }^{2}$ Foods for Health Institute, University of California, Davis, One Shields Ave, Davis, CA 95616, USA. ${ }^{3}$ Western Center for Food Safety, University of California, Davis, Davis, CA 95616, USA. ${ }^{4}$ USDA ARS Western Human Nutrition Research Center, 430 West Health Sciences Dr, Davis, CA 95616, USA. ${ }^{5}$ Genome Center, University of California, 451 Health Sciences Dr., Davis, California 95616, USA. ${ }^{6}$ Department of Nutrition, University of California, Davis, One Shields Ave., Davis, CA 95616, USA. ${ }^{7}$ Department of Viticulture and Enology, Robert Mondavi Institute for Wine and Food Science, University of California, Davis, One Shields Ave, Davis, CA 95616, USA

Received: 7 March 2020 Accepted: 11 May 2020

Published online: 26 June 2020

\section{References}

1. Davis BJ, Li CX, Nachman KE: A literature review of the risks and benefits of consuming raw and pasteurized cow's milk. In.; 2014.

2. Potter ME, Kaufmann AF, Blake PA, Feldman RA. Unpasteurized milk. The hazards of a health fetish. JAMA. 1984;252(15):2048-52.

3. Jay-Russell MT. Raw (unpasteurized) milk: are health-conscious consumers making an unhealthy choice? Clin Infect Dis. 2010:51(12):1418-9.

4. Loss G, Apprich S, Waser M, Kneifel W, Genuneit J, Buchele G, et al. The protective effect of farm milk consumption on childhood asthma and atopy: the GABRIELA study. J Allergy Clin Immunol. 2011;128(4):766-73 e764.

5. Waser M, Michels KB, Bieli C, Floistrup H, Pershagen G, von Mutius E, et al. Inverse association of farm milk consumption with asthma and allergy in rural and suburban populations across Europe. Clin Exp Allergy. 2007;37(5): $661-70$.

6. Loss G, Depner M, Ulfman LH, van Neerven RJ, Hose AJ, Genuneit J, et al. Consumption of unprocessed cow's milk protects infants from common respiratory infections. J Allergy Clin Immunol. 2015;135(1):56-62.

7. Oliver SP, Boor KJ, Murphy SC, Murinda SE. Food safety hazards associated with consumption of raw milk. Foodborne Pathog Dis. 2009;6(7):793-806.

8. Langer AJ, Ayers T, Grass J, Lynch M, Angulo FJ, Mahon BE. Nonpasteurized dairy products, disease outbreaks, and state laws-United States, 1993-2006. Emerg Infect Dis. 2012;18(3):385-91.

9. Mungai EA, Behravesh CB, Gould LH. Increased outbreaks associated with nonpasteurized milk, United States, 2007-2012. Emerg Infect Dis. 2015;21(1): 119-22.

10. Kuehn B. Drug-resistant infections from raw milk. JAMA. 2018:319(12):1191

11. Costard S, Espejo L, Groenendaal H, Zagmutt FJ. Outbreak-related disease burden associated with consumption of unpasteurized cow's milk and cheese, United States, 2009-2014. Emerg Infect Dis. 2017;23(6):957-64. 
12. Caudell MA, Mair C, Subbiah M, Matthews L, Quinlan RJ, Quinlan MB, et al. Identification of risk factors associated with carriage of resistant Escherichia coli in three culturally diverse ethnic groups in Tanzania: a biological and socioeconomic analysis. Lancet Planet Health. 2018;2(11):e489-97.

13. Godziszewska J, Pogorzelska-Nowicka E, Brodowska M, Jagura-Burdzy G, Wierzbicka A: Detection in raw cow's milk of coliform bacteria - reservoir of antibiotic resistance. LWT - Food Science and Technology 2018.

14. Munsch-Alatossava P, Alatossava T. Antibiotic resistance of raw-milkassociated psychrotrophic bacteria. Microbiol Res. 2007;162(2):115-23.

15. Burakoff A, Brown K, Knutsen J, Hopewell C, Rowe S, Bennett C, et al. Outbreak of fluoroquinolone-resistant Campylobacter jejuni infections associated with raw milk consumption from a herdshare dairy - Colorado, 2016. Mmwr-Morbid Mortal W. 2018;67(5):146-8.

16. Alexa EA: Dairy products and dairy-processing environments as a reservoir of antibiotic resistance and quorum-quenching determinants as revealed through functional metagenomics. mSystems 2020.

17. Quigley L, 'Sullivan O O, Stanton C, Beresford TP, Ross RP, Fitzgerald GF, et al. The complex microbiota of raw milk. FEMS Microbiol Rev. 2013;37(5):664-98.

18. Li N, Wang Y, You C, Ren J, Chen W, Zheng H, et al. Variation in raw milk microbiota throughout 12 months and the impact of weather conditions. Sci Rep. 2018;8(1):2371.

19. Kable ME, Srisengfa Y, Laird M, Zaragoza J, McLeod J, Heidenreich J, Marco $\mathrm{ML}$ : The core and seasonal microbiota of raw bovine milk in tanker trucks and the impact of transfer to a milk processing facility. MBio 2016, 7(4).

20. Clabber milk-what it is, why you should eat it and how to make it [https:// www.butterforall.com/traditional-cooking-traditional-living/clabber-milk/.

21. David SD. Raw milk in court: implications for public health policy and practice. Public Health Rep. 2012;127(6):598-601.

22. CDC: Foodborne active surveillance network (FoodNet) population survey atlas of exposures. In.: Atlanta, Georgia: U.S. Department of Health and Human Services, Centers for Disease Control and Prevention, 2006-2007; 2007.

23. IDFA. Pasteurization; 2020.

24. CDFA. Regulatory requirements for distribution of milk for raw consumption in Californialn. Edited by Agriculture CDoFa; 2015.

25. Yassine H, Bientz L, Cros J, Goret J, Bebear C, Quentin C, et al. Experimental evidence for IS1294b-mediated transposition of the blaCMY-2 cephalosporinase gene in Enterobacteriaceae. J Antimicrob Chemother. 2015;70(3):697-700.

26. Scheldeman P, Pil A, Herman L, De Vos P, Heyndrickx M. Incidence and diversity of potentially highly heat-resistant spores isolated at dairy farms. Appl Environ Microbiol. 2005;71(3):1480-94.

27. Martin NH, Kent DJ, Evanowski RL, Zuber Hrobuchak TJ, Wiedmann M. Bacterial spore levels in bulk tank raw milk are influenced by environmental and cow hygiene factors. J Dairy Sci. 2019.

28. Adams DM, Barach JT, Speck ML. Heat resistant proteases produced in milk by psychrotrophic bacteria of dairy origin. J Dairy Sci. 1975;58(6):828-34.

29. De Jonghe V, Coorevits A, Van Hoorde K, Messens W, Van Landschoot A, De Vos P, et al. Influence of storage conditions on the growth of Pseudomonas species in refrigerated raw milk. Appl Environ Microbiol. 2011;77(2):460-70.

30. Liu J, Taft DH, Maldonado-Gomez MX, Johnson D, Treiber ML, Lemay DG, et al. The fecal resistome of dairy cattle is associated with diet during nursing. Nat Commun. 2019;10(1):4406.

31. Doyle CJ, Gleeson D, O'Toole PW, Cotter PD: Impacts of seasonal housing and teat preparation on raw milk microbiota: a high-throughput sequencing study. Appl Environ Microbiol 2017, 83(2).

32. Forsberg KJ, Patel S, Gibson MK, Lauber CL, Knight R, Fierer N, et al. Bacterial phylogeny structures soil resistomes across habitats. Nature. 2014;509(7502):612-6.

33. CDC: Antibiotic resistance threats in the United States, 2019. In. Atlanta, GA: U.S. Department of Health and Human Services, CDC: Atlanta, GA: U.S. Department of Health and Human Services, CDC; 2019.

34. WHO: Antimicrobial resistance: global report on surveillance. In. World Health Organization, 20 Avenue Appia,1211 Geneva 27, Switzerland; 2014.

35. Williams PCM, Isaacs D, Berkley JA. Antimicrobial resistance among children in sub-Saharan Africa. Lancet Infect Dis. 2018;18(2):E33-44.

36. Dangour AD, Watson L, Cumming O, Boisson S, Che Y, Velleman $Y$, et al. Interventions to improve water quality and supply, sanitation and hygiene practices, and their effects on the nutritional status of children. Cochrane Db Syst Rev. 2013;8.

37. Salter SJ, Cox MJ, Turek EM, Calus ST, Cookson WO, Moffatt MF, et al. Reagent and laboratory contamination can critically impact sequence-based microbiome analyses. BMC Biol. 2014;12:87.
38. Alcock BP, Raphenya AR, Lau TTY, Tsang KK, Bouchard M, Edalatmand A, et al. CARD 2020: antibiotic resistome surveillance with the comprehensive antibiotic resistance database. Nucleic Acids Res. 2020;48(D1):D517-25.

39. Gweon HS. The impact of sequencing depth on the inferred taxonomic composition and AMR gene content of metagenomic samples. Environ Microbiome. 2019.

40. 10 reasons to drink your milk raw [https://nourishedkitchen.com/10-reasonsdrink-raw-milk]

41. Orecchio C. Using raw milk for digestive and immune healing. The Whole Journey vol: In; 2019

42. (NCSL) NCOSL: NCSL updated summary of raw milk statutes and administrative codes. In.; 2016.

43. Obermajer T, Lipoglavsek L, Tompa G, Treven P, Lorbeg PM, Matijasic BB, et al. Colostrum of healthy Slovenian mothers: microbiota composition and bacteriocin gene prevalence. PLoS One. 2014;10(4):e0123324.

44. Clarridge JE, 3rd: Impact of $16 \mathrm{~S}$ rRNA gene sequence analysis for identification of bacteria on clinical microbiology and infectious diseases. Clin Microbiol Rev 2004, 17(4):840-862, table of contents.

45. CLSI: Performance standards for antimicrobial susceptibility testing. In. Edited by Wayne PCaLSI, 28th Edition edn; 2018.

46. Zankari E, Hasman H, Cosentino S, Vestergaard M, Rasmussen S, Lund O, et al. Identification of acquired antimicrobial resistance genes. J Antimicrob Chemother. 2012;67(11):2640-4.

47. Carattoli A, Zankari E, Garcia-Fernandez A, Larsen MV, Lund O, Villa L, et al. In silico detection and typing of plasmids using plasmidFinder and plasmid multilocus sequence typing. Antimicrob Agents Ch. 2014;58(7):3895-903.

48. Liu JX, Yang YX, Li YX, Liu D, Tuo HM, Wang HN, et al. Isolation of an IncP-1 plasmid harbouring mcr-1 from a chicken isolate of Citrobacter braakii in China. Int J Antimicrob Ag. 2018;51(6):936-40

49. Zhao SH, White DG, McDermott PF, Friedman S, English L, Ayers S, et al. Identification and expression of cephamycinase Bla (CMY) genes in Escherichia coli and salmonella isolates from food animals and ground meat. Antimicrob Agents Ch. 2001:45(12):3647-50.

50. Andrews S: A quality control tool for high throughput sequence data. In.; 2010.

51. Davis NM, Proctor DM, Holmes SP, Relman DA, Callahan BJ. Simple statistical identification and removal of contaminant sequences in marker-gene and metagenomics data. Microbiome. 2018;6(1):226.

52. Bolyen E, Rideout JR, Dillon MR, Bokulich NA, Abnet CC, Al-Ghalith GA, et al. Reproducible, interactive, scalable and extensible microbiome data science using QIIME 2. Nat Biotechnol. 2019;37(8):852-7.

53. Callahan BJ, McMurdie PJ, Rosen MJ, Han AW, Johnson AJ, Holmes SP. DADA2: high-resolution sample inference from Illumina amplicon data. Nat Methods. 2016;13(7):581-3.

54. Douglas Bates MM. Ben Bolker, Steve Walker: fitting linear mixed-effects models using Ime4. J Stat Softw. 2015.

55. Torsten Hothorn FBaPW: Simultaneous inference in general parametric models. Biometrical Journal 2008(50(3), 346--363).

56. Lenth RV: Least-squares means: The R package Ismeans. Journal of Statistical Software 2016(69(1), 1-33).

57. Paulson JN, Stine OC, Bravo HC, Pop M. Differential abundance analysis for microbial marker-gene surveys. Nat Methods. 2013;10(12):1200-2.

58. Core R. Team: R: a language and environment for statistical computing. In. Vienna, Austria: R Foundation for statistical. Computing. 2019.

59. Jari Oksanen FGB, Michael Friendly, Roeland Kindt, Pierre Legendre, Dan McGlinn PRM, R. B. O'Hara, Gavin L. Simpson, Peter Solymos, M. Henry H. Stevens, Eduard Szoecs and Helene Wagner: vegan: community ecology package. 2019.

60. Quast C, Pruesse E, Yilmaz P, Gerken J, Schweer T, Yarza P, et al. The SILVA ribosomal RNA gene database project: improved data processing and web-based tools. Nucleic Acids Res. 2013; 41(Database issue):D590-6.

61. Bolger AM, Lohse M, Usadel B. Trimmomatic: a flexible trimmer for Illumina sequence data. Bioinformatics. 2014;30(15):2114-20.

62. Magoc T, Salzberg SL. FLASH: fast length adjustment of short reads to improve genome assemblies. Bioinformatics. 2011;27(21):2957-63.

63. Wood DE, Salzberg SL: Kraken: ultrafast metagenomic sequence classification using exact alignments. Genome Biol 2014, 15(3).

64. O'Leary NA, Wright MW, Brister JR, Ciufo S, Haddad D, McVeigh R, et al. Reference sequence (RefSeq) database at NCBI: current status, taxonomic expansion, and functional annotation. Nucleic Acids Res. 2016:44(D1):D733-45.

65. Stewart RD, Auffret MD, Warr A, Walker AW, Roehe R, Watson M. Compendium of 4,941 rumen metagenome-assembled genomes for rumen microbiome biology and enzyme discovery. Nat Biotechnol. 2019;37(8):953-61. 
66. Lu J, Breitwieser FP, Thielen P, Salzberg SL. Bracken: estimating species abundance in metagenomics data. Peerj Comput Sci. 2017.

67. Lakin SM, Dean C, Noyes NR, Dettenwanger A, Ross AS, Doster E, et al. MEGARes: an antimicrobial resistance database for high throughput sequencing. Nucleic Acids Res. 2017;45(D1):D574-80.

68. Li H, Durbin R. Fast and accurate short read alignment with burrowswheeler transform. Bioinformatics. 2009;25(14):1754-60.

69. Doster E, Lakin SM, Dean CJ, Wolfe C, Young JG, Boucher C, et al. MEGARes 2.0: a database for classification of antimicrobial drug, biocide and metal resistance determinants in metagenomic sequence data. Nucleic Acids Res. 2020;48(D1):D561-9.

70. Taft DH, Liu J, Maldonado-Gomez MX, Akre S, Huda MN, Ahmad SM, Stephensen CB, Mills DA: Bifidobacterial dominance of the gut in early life and acquisition of antimicrobial resistance. mSphere 2018, 3(5).

71. Li B, Yang Y, Ma L, Ju F, Guo F, Tiedje JM, et al. Metagenomic and network analysis reveal wide distribution and co-occurrence of environmental antibiotic resistance genes. ISME J. 2015;9(11):2490-502

72. Bengtsson-Palme J, Hartmann M, Eriksson KM, Pal C, Thorell K, Larsson DG, et al. METAXA2: improved identification and taxonomic classification of small and large subunit rRNA in metagenomic data. Mol Ecol Resour. 2015; 15(6):1403-14

73. Li D, Liu CM, Luo R, Sadakane K, Lam TW. MEGAHIT: an ultra-fast singlenode solution for large and complex metagenomics assembly via succinct de Bruijn graph. Bioinformatics. 2015;31(10):1674-6.

74. Droge J, Gregor I, McHardy AC. Taxator-tk: precise taxonomic assignment of metagenomes by fast approximation of evolutionary neighborhoods. Bioinformatics. 2015;31(6):817-24.

75. Shannon P, Markiel A, Ozier O, Baliga NS, Wang JT, Ramage D, et al. Cytoscape: a software environment for integrated models of biomolecular interaction networks. Genome Res. 2003;13(11):2498-504.

\section{Publisher's Note}

Springer Nature remains neutral with regard to jurisdictional claims in published maps and institutional affiliations.

Ready to submit your research? Choose BMC and benefit from:

- fast, convenient online submission

- thorough peer review by experienced researchers in your field

- rapid publication on acceptance

- support for research data, including large and complex data types

- gold Open Access which fosters wider collaboration and increased citations

- maximum visibility for your research: over $100 \mathrm{M}$ website views per year

At $\mathrm{BMC}$, research is always in progress.

Learn more biomedcentral.com/submissions 